\title{
Use of Non-benzodiazepine Hypnotics Is Associated with Decreased Risk of Coronary Artery Disease
}

\author{
Xiang Zhou ${ }^{1}$, Yufeng Zhang ${ }^{2}$, Jianchang Chen $^{1}$ and Weiting $\mathrm{Xu}^{1}$
}

\begin{abstract}
Background It has been reported that the use of benzodiazepines (BDZs) is associated with an increased risk of coronary artery disease (CAD). However, it is still unclear whether or not non-BDZs use has the same adverse effect on the cardiovascular system.

Methods We conducted a hospital-based case-control study with $864 \mathrm{CAD}$ patients and 1,008 controls to explore the association between non-BDZs use and CAD risk in Chinese Han population.

Results Non-BDZs use was found to be associated with a decreased risk of CAD (adjusted odds ratio, $\mathrm{OR}=$ 0.73; $95 \%$ confidence interval, $\mathrm{CI}=0.54-0.98$ ). Adjusted ORs were 0.91 (95\% $\mathrm{CI}=0.63-1.32$ ) for using nonBDZs 0 to 5 years, $0.64(95 \% \mathrm{CI}=0.38-0.97)$ for 5 to 10 years, and $0.42(95 \% \mathrm{CI}=0.18-0.85)$ for $>10$ years. The risk of CAD tended to decrease with an increase in duration of non-BDZs use ( $\mathrm{p}<0.001$ for trend). Conclusion Our study demonstrates that non-BDZs use is associated with a decreased risk of CAD. The potential cardiovascular protective mechanisms of non-BDZs should be investigated further.
\end{abstract}

Key words: coronary artery disease, non-benzodiazepine, angiography

(Intern Med 51: 829-832, 2012)

(DOI: 10.2169/internalmedicine.51.6942)

\section{Introduction}

Non-benzodiazepines (non-BDZs), which selectively bind to type $1 \mathrm{BDZ}$ receptors in the central nervous system, are commonly prescribed to treat chronic insomnia due to their efficiency, safety, and lower potential to cause dependence. Unlike BDZs, the non-BDZs have minimal impact on sleep stages and no rapid eye movement sleep rebound. When indirectly compared with BDZs, the non-BDZs are similarly effective but they have less overall risk of adverse effects (1). A previous population-based study reported that BDZs use was associated with increased risk of ischemic heart disease (relative risk $=2.0$, 90\% confidence interval= 1.1-3.9) (2). However, there have not been any studies that have evaluated the relation between non-BDZs use and coronary artery disease (CAD). Therefore, the present casecontrol study was designed to explore the potential association between non-BDZs use and CAD risk in Chinese Han population.

\section{Materials and Methods}

\section{Study population}

The study enrolled 864 consecutive patients with CAD admitted to the First Affiliated Hospital of Nanjing Medical University. The diagnosis of CAD was confirmed by coronary angiography performed with the Judkins technique using a quantitative coronary angiographic system (3). CAD was defined as angiographic evidence of at least one segment of a major coronary artery including the left anterior descending, left circumflex or right coronary artery with more than $50 \%$ organic stenosis (4). Patients with CAD were divided into 1-, 2-, and 3-vessel disease subgroups according to the number of significantly stenosed vessels with reference to the Coronary Artery Surgery Study classification. This study also included 1,008 control subjects randomly selected from outpatients who underwent regular physical examinations during the same time in the same

${ }^{1}$ Department of Cardiology, The Second Affiliated Hospital of Soochow University, China and ${ }^{2}$ Department of Internal Medicine, Jiangyin Hospital of Traditional Chinese Medicine, China

Received for publication November 15, 2011; Accepted for publication January 5, 2012

Correspondence to Dr. Jianchang Chen, shaoh@163.com 
Table 1. Baseline Characteristics of CAD Patients and Controls

\begin{tabular}{|c|c|c|c|}
\hline \multirow[t]{2}{*}{ Characteristics } & \multicolumn{2}{|c|}{ CAD } & \multirow[t]{2}{*}{$\mathrm{p}$} \\
\hline & $\begin{array}{c}\text { Yes } \\
(\mathrm{n}=864)\end{array}$ & $\begin{array}{c}\text { No } \\
(\mathrm{n}=1008)\end{array}$ & \\
\hline Age (years) & $64.2 \pm 8.5$ & $58.3 \pm 10.2$ & $<0.001$ \\
\hline Sex (male) & $672(77.8)$ & $716(71.0)$ & $<0.001$ \\
\hline Body mass index $\left(\mathrm{kg} / \mathrm{m}^{2}\right)$ & $25.02 \pm 2.80$ & $23.63 \pm 2.54$ & $<0.001$ \\
\hline Hypertension & $507(58.7)$ & $412(40.9)$ & $<0.001$ \\
\hline Diabetes & $235(27.2)$ & $168(16.7)$ & $<0.001$ \\
\hline Dyslipidemia & $299(34.6)$ & $232(23.0)$ & $<0.001$ \\
\hline Smoking & $528(61.1)$ & $362(35.9)$ & $<0.001$ \\
\hline Physically active & $366(42.4)$ & $557(55.3)$ & $<0.001$ \\
\hline \multicolumn{4}{|l|}{ Number of diseased vessels } \\
\hline Single vessel & $330(38.2)$ & - & - \\
\hline Double vessels & $281(32.5)$ & - & - \\
\hline Triple vessels & $253(29.3)$ & - & - \\
\hline
\end{tabular}

hospital. Those controls with a history of angina, symptoms or signs of other atherosclerotic vascular diseases and an abnormal electrocardiogram were excluded. All subjects enrolled in this study were of Han Chinese origin and residing in or near Jiangsu Province. They had no history of significant concomitant diseases including cardiomyopathy, bleeding disorders, renal failure, previous thoracic irradiation therapy and malignant diseases. This study was approved by the institutional ethics committees of the First Affiliated Hospital of Nanjing Medical University and informed consent was obtained from each participant.

\section{Data collection}

In the present study, patients were regarded as physically active if they engaged in aerobic activities for $>30$ minutes (walking, bicycling, running, swimming, etc.) $\geq 3$ times/ week. Weight and height measurements were taken after the patients removed their shoes and outer garments and put on an examination gown. Height was measured to the nearest $0.1 \mathrm{~cm}$ using a wall-mounted stadiometer. Weight was measured to the nearest $0.1 \mathrm{~kg}$ using a hospital balance beam scale. Body mass index (BMI) was calculated as weight (kilograms) divided by height (meters) squared. Obesity was defined as a $\mathrm{BMI} \geq 28 \mathrm{~kg} / \mathrm{m}^{2}$. Biochemical data, including total cholesterol concentration, triglyceride concentration, and fasting blood glucose concentration, were collected from patients' most recent medical records. Dyslipidemia was defined as a serum total cholesterol concentration $>5.72 \mathrm{mmol} /$ $\mathrm{L}$ or triglyceride concentration $>1.70 \mathrm{mmol} / \mathrm{L}$ or the use of lipid-lowering therapy. Diabetes was defined as a fasting blood glucose concentration of $\geq 7.0 \mathrm{mmol} / \mathrm{L}$ or the use of antidiabetic drug therapy. Blood pressure was measured in the right arm with the participant seated and the arm bare using an automatic sphygmomanometer. Two readings were recorded for each subject and the average was recorded. Hypertension was defined as a systolic blood pressure $\geq 140$ $\mathrm{mmHg}$ or a diastolic blood pressure $\geq 90 \mathrm{mmHg}$ or receiving antihypertensive treatment. Subjects who formerly or currently smoked $\geq 10$ cigarettes/day for $\geq 2$ years were defined as smokers. The information about BDZs and non-
BDZs use was collected from pharmacy record of each participant.

\section{Statistical analysis}

In the present study, age and BMI data were treated as continuous variables. Sex, hypertension, diabetes, dyslipidemia, smoking, and physical activity were treated as categorical variables. Odds ratio (OR) and $95 \%$ confidence interval (CI) were calculated to indicate the relation between nonBDZs use and CAD risk. Multiple logistic regression analysis was used to adjust for age, sex, BMI, hypertension, diabetes, dyslipidemia, smoking, and physical activity. A p value $<0.05$ was considered statistically significant. All statistical analyses were carried out using SPSS 13.0 (SPSS, Inc., Chicago, IL).

\section{Results}

The characteristics of our study subjects are listed in Table 1. Patients with CAD were much older, smoked more cigarettes, had higher BMI and less physical activity, and were more likely to be hypertensive, diabetic and dyslipidemic than the control subjects. In terms of coronary angiographic findings, 330 (38.2\%) CAD cases had single-vessel disease, 281 (32.5\%) had double-vessel disease and 253 $(29.3 \%)$ had triple-vessel disease.

Table 2 shows that BDZs use was associated with an increased risk of $\mathrm{CAD}$ (adjusted $\mathrm{OR}=1.39$, 95\% $\mathrm{CI}=1.12$ 1.81 ), while non-BDZs use was associated with decreased risk of CAD (adjusted OR=0.73, 95\% CI=0.54-0.98).

The relation between duration of non-BDZs use and risk of CAD is presented in Table 3. Adjusted ORs were 0.91 (95\% $\mathrm{CI}=0.63-1.32$ ) for using non-BDZs 0 to 5 years, 0.64 (95\% $\mathrm{CI}=0.38-0.97)$ for 5 to 10 years, and $0.42(95 \% \mathrm{CI}=$ $0.18-0.85)$ for $>10$ years. The risk of CAD tended to decrease with an increase in duration of non-BDZs use $(\mathrm{p}<$ 0.001 for trend).

Table 4 shows the comparison of non-BDZs users and non-users in terms of CAD risk factors. There were no significant differences in CAD risk factors between users and 
Table 2. Association of BDZs and non-BDZs Use with CAD

\begin{tabular}{lcccc}
\hline Groups, n (\%) & Cases & Controls & Crude OR & Adjusted $^{\text {a }}$ OR \\
\cline { 2 - 5 } & $(\mathrm{n}=864)$ & $(\mathrm{n}=1008)$ & $(95 \% \mathrm{CI})$ & $(95 \% \mathrm{CI})$ \\
\hline Non-users ${ }^{\mathrm{b}}$ & $578(66.9)$ & $692(68.6)$ & 1.00 & 1.00 \\
BDZs users & $182(21.1)$ & $161(16.0)$ & $1.35(1.07-1.72)$ & $1.39(1.12-1.81)$ \\
Non-BDZs users & $104(12.0)$ & $155(15.4)$ & $0.80(0.61-1.05)$ & $0.73(0.54-0.98)$ \\
\hline${ }^{\mathrm{a}}$ Adjustment for age, sex, body & mass index, hypertension, diabetes, dyslipidemia, \\
smoking, and physical activity. & & \\
${ }^{\mathrm{b}}$ Subjects who neither used BDZs nor non-BDZs. & \\
BDZ, benzodiazepine; CAD, coronary artery disease; &
\end{tabular}

Table 3. Duration of non-BDZs Use and CAD Risk

\begin{tabular}{lllll}
\hline Number of years & \multicolumn{1}{c}{ Cases } & \multicolumn{1}{c}{ Controls } & \multicolumn{1}{c}{ Crude OR } & Adjusted ${ }^{\mathrm{a}} \mathrm{OR}$ \\
\cline { 2 - 5 } using non-BDZs & $(\mathrm{n}=864)$ & $(\mathrm{n}=1008)$ & $(95 \% \mathrm{CI})$ & $(95 \% \mathrm{CI})$ \\
\hline 0 & $760(88.0)$ & $853(84.6)$ & 1.00 & 1.00 \\
$0-5$ & $58(6.7)$ & $69(6.8)$ & $0.94(0.66-1.36)$ & $0.91(0.63-1.32)$ \\
$5-10$ & $34(3.9)$ & $57(5.7)$ & $0.67(0.43-1.04)$ & $0.64(0.38-0.97)$ \\
$>10$ & $12(1.4)$ & $29(2.9)$ & $0.46(0.24-0.92)$ & $0.42(0.18-0.85)$ \\
$\mathrm{p}$ for trend & & 0.007 & $<0.001$ \\
\hline${ }^{a}$ Adjustment for age, sex, body mass index, hypertension, diabetes, dyslipidemia, \\
smoking, and physical activity. \\
BDZ, benzodiazepine; CAD, coronary artery disease; \\
OR, odds ratio; CI, confidence interval
\end{tabular}

Table 4. Comparison of non-BDZs Users and non-Users in Terms of CAD Risk Factors

\begin{tabular}{llll}
\hline CAD risk factors & \multicolumn{2}{c}{ Non-BDZs users } & $\mathrm{p}$ \\
\cline { 2 - 3 } & \multicolumn{1}{c}{ Yes } & No \\
& $(\mathrm{n}=259)$ & $60.8 \pm 12.4$ & $\mathrm{NS}$ \\
\hline Age (years) & $58.7 \pm 15.6$ & $24.23 \pm 2.87$ & $\mathrm{NS}$ \\
Body mass index $\left(\mathrm{kg} / \mathrm{m}^{2}\right)$ & $25.46 \pm 3.25$ & $784(48.6)$ & $\mathrm{NS}$ \\
Hypertension & $135(52.1)$ & $343(21.3)$ & $\mathrm{NS}$ \\
Diabetes & $60(23.2)$ & $463(28.7)$ & $\mathrm{NS}$ \\
Dyslipidemia & $68(26.3)$ & $763(47.3)$ & $\mathrm{NS}$ \\
Smoking & $127(49.0)$ & $802(49.7)$ & $\mathrm{NS}$ \\
Physically active & $121(46.7)$ & $802)$ \\
\hline
\end{tabular}

Data are expressed as mean \pm SD or frequencies (percentages).

$\mathrm{BDZ}$, benzodiazepine; CAD, coronary artery disease

non-users of non-BDZs.

\section{Discussion}

$\mathrm{CAD}$ is a major cause of morbidity and mortality in humans worldwide. Many risk factors for CAD have been identified in the past few decades, including smoking, hypertension, dyslipidemia, diabetes, obesity, and physical inactivity (5-9). To date, there have not been any studies that have evaluated the relation between non-BDZs use and CAD risk. Therefore, we conducted a hospital-based casecontrol study with $864 \mathrm{CAD}$ patients and 1,008 controls to explore the association between non-BDZs use and CAD risk in Chinese Han population.

The present findings revealed that BDZs use was associated with an increased risk of CAD, which was in accordance with the results of Lapane et al. (2). However, nonBDZs use was found to be associated with a decreased risk of CAD in this study. Zolpidem and zaleplon were the most commonly prescribed non-BDZs among the study subjects. The risk of CAD tended to decrease with an increase in duration of non-BDZs use, suggesting that non-BDZs may have some protective effect on the cardiovascular system.

A previous review of epidemiologic studies reported that insomnia was associated with an increased risk of coronary heart disease (10). In addition, there is growing evidence that anxiety is an independent risk factor for the development of CAD (11-14). Therefore, it is possible that nonBDZs can reduce the risk of CAD by relieving insomnia and anxiety. However, it is difficult to explain why the BDZs use was associated with an increased risk of CAD, since they are also commonly prescribed to treat chronic insomnia and anxiety among older people in China. The opposite effects of BDZs and non-BDZs on CAD may be partly due to their pharmacological difference. When compared with BDZs, the non-BDZs appear to be safer, have a lower risk of dependence, and have less overall risk of adverse effects (1). Further investigations are necessary to explore the potential cardiovascular protective mechanisms of non-BDZs.

Our study had some limitations. First, the relatively small sample size of this study may limit the statistical power. However, this internally consistent pilot study certainly provides valuable insight and interesting information and may serve to guide future studies in this area. Second, although we selected controls from individuals with no history of angina, no symptoms or signs of other atherosclerotic vascular diseases and normal electrocardiogram, without performing coronary angiography, we could not rule out CAD completely.

In conclusion, our study demonstrates that non-BDZs use is associated with a decreased risk of CAD. The potential 
cardiovascular protective mechanisms of non-BDZs should be investigated further.

The authors state that they have no Conflict of Interest (COI).

\section{References}

1. Scharf MB, Roth T, Vogel GW, Walsh JK. A multicenter, placebocontrolled study evaluating zolpidem in the treatment of chronic insomnia. J Clin Psychiatry 55: 192-199, 1994.

2. Lapane KL, Zierler S, Lasater TM, Barbour MM, Carleton R, Hume AL. Is the use of psychotropic drugs associated with increased risk of ischemic heart disease? Epidemiology 6: 376-381, 1995.

3. Santamore WP, Kahl FR, Kutcher MA, et al. A microcomputer based automated, quantitative coronary angiographic analysis system. Ann Biomed Eng 16: 367-377, 1988.

4. Austen WG, Edwards JE, Frye RL, et al. A reporting system on patients evaluated for coronary artery disease: Report of the Ad Hoc Committee for Grading of Coronary Artery Disease, Council on Cardiovascular Surgery, American Heart Association. Circulation 51: S5-S40, 1975.

5. Wilson PW. Established risk factors and coronary artery disease: the Framingham Study. Am J Hypertens 7: 7S-12S, 1994.

6. Price JF, Fowkes FG. Risk factors and the sex differential in coro- nary artery disease. Epidemiology 8: 584-591, 1997.

7. Gensini GF, Comeglio M, Colella A. Classical risk factors and emerging elements in the risk profile for coronary artery disease. Eur Heart J 19: A53-A61, 1998.

8. Virmani R, Farb A, Burke AP. Risk factors in the pathogenesis of coronary artery disease. Compr Ther 24: 519-529, 1998.

9. Knopp RH. Risk factors for coronary artery disease in women. Am J Cardiol 89: 28E-34E, 2002.

10. Schwartz S, McDowell Anderson W, Cole SR, Cornoni-Huntley J, Hays JC, Blazer D. Insomnia and heart disease: a review of epidemiologic studies. J Psychosom Res 47: 313-333, 1999.

11. Kubzansky LD, Kawachi I. Going to the heart of the matter: do negative emotions cause coronary heart disease? J Psychosom Res 48: 323-337, 2000.

12. Vogelzangs N, Seldenrijk A, Beekman AT, van Hout HP, de Jonge P, Penninx BW. Cardiovascular disease in persons with depressive and anxiety disorders. J Affect Disord 125: 241-248, 2010.

13. Nabi H, Hall M, Koskenvuo M, et al. Psychological and somatic symptoms of anxiety and risk of coronary heart disease: the health and social support prospective cohort study. Biol Psychiatry 67: 378-385, 2010.

14. Roest AM, Martens EJ, de Jonge P, Denollet J. Anxiety and risk of incident coronary heart disease: a meta-analysis. J Am Coll Cardiol 56: 38-46, 2010.

(C) 2012 The Japanese Society of Internal Medicine http://www.naika.or.jp/imindex.html 